\title{
ПОЧЕЧНАЯ КОЛИКА
}

В.В. Скворцов, докт. мед. наук, А.В. Тумаренко, Е.И. Калинченко, канд. мед. наук,

Т.Э. Салтовская, А.А. Чернышова, М.А. Лукина

Волгоградский государственный медицинский университет, Российская Федерация, 400066, Волгоград, площадь Павших Бойцов, д. 1

E-mail: vskvortsov1@ya.ru

Представлены вопросы этиологии, патогенеза, клинической симптоматики, подходы к диагностике и терапии приступа почечной колики и мочекаменной болезни.

Ключевые слова: мочекаменная болезнь, почечная колика, диагностика, неотложная помощь, спазмолитики, холинолитики, наркотические анальгетики, новокаиновые блокады, тепловые процедуры, инфузионная терапия.

Для цитирования: Скворцов В.В., Тумаренко А.В., Калинченко Е.И., Салтовская Т.Э., Чернышова А.А., Лукина М.А. Почечная колика. Медицинская сестра. 2018; 20 (6): 3-5. https://doi.org/10.29296/25879979-2018-06-01

Почечная колика представляет собой приступ резких, невыносимых болей в поясничной области, которые развиваются вследствие остро возникшего препятствия пассажу мочи на пути от почки до мочевого пузыря.

Риск возникновения почечной колики в популяции составляет 1-10\% (Labrecque, Dostaleretab, 1994). Чаще всего она возникает при мочекаменной болезни, но в 5\% случаев развивается при других заболеваниях почек - пиелонефрите и стенозе лоханочно-мочеточникового сегмента. Возможно также (10\% случаев) развитие почечной колики при обструкции мочеточника вследствие других причин, включая гинекологические заболевания и операции, уровазальный конфликт, ретроперитонеальный фиброз.

Острое затруднение оттока мочи из верхних мочевых путей ведет к переполнению чашечно-лоханочной системы мочой выше места окклюзии, повышению давления в почечных лоханках и нарушению кровообращения в почке. При почечной колике из-за механического повреждения почечной ткани вследствие обструкции высвобождается большое количество вазоактивных медиаторов воспаления (например, тромбоксан А) и факторов роста, что приблизительно через 4 ч от начала приступа приводит к сужению приносящих артериол, снижению почечного кровотока и как следствие - к ишемии с последующим поврежде- нием клеток собирательных канальцев (см. рисунок).

Таким образом, почечная колика - не простой болевой синдром, а серьезное нарушение многих функций почки, которые могут вести к тяжелым осложнениям, представляющим опасность для жизни пациента (острый гнойный пиелонефрит, бактериемический шок, околопочечная флегмона).

Болевой приступ может развиться ночью, в период сна; иногда начало почечной колики пациенты связывают с физической нагрузкой, тряской ездой, длительной ходьбой, приемом мочегонных лекарств или большого объема жидкости. Из поясницы боль может распространяться в мезогастральную, подвздошную область, бедро, прямую кишку, у мужчин - в половой член и мошонку, у женщин - в половые губы и промежность.

Болевой приступ при почечной колике может длиться от 3 до $\geq 18$ ч; при этом интенсивность боли, ее локализация и иррадиация могут изменяться.

Характерно беспокойное поведение больных, которые стонут, мечутся и принимают самые не-

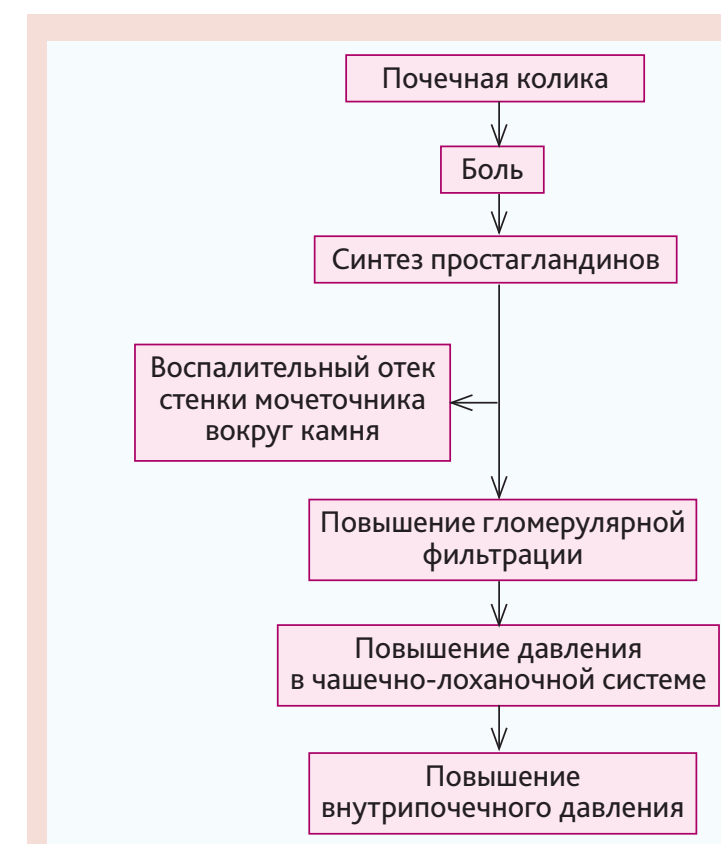

Патогенез почечной колики 
вероятные позы, так как не могут найти положения, в котором бы интенсивность болей уменьшилась. Больной мечется, иногда наклоняет туловище, удерживая ладонь на пояснице со стороны боли. Появляются бледность, холодный пот. Иногда повышается артериальное давление. Дизурические явления довольно часто (но не всегда) сопутствуют приступу почечной колики. Дизурия проявляется учащенным, болезненным мочеиспусканием: чем ближе к мочевому пузырю локализуется камень, тем резче дизурия.

Нередко почечную колику сопровождают тошнота, многократная рвота, задержка стула и газов, вздутие живота (гастроинтестинальный синдром), что затрудняет диагноз.

Сильная боль при почечной колике может вызвать развитие шокового состояния (гипотонию, бледность кожных покровов, брадикардию, холодный пот).

Паралитический илеус, часто сопровождающий приступ почечной колики, при схваткообразном усилении болей и беспокойном поведении больных иногда принимают за кишечную непроходимость механического характера. Однако внимательное обследование больного с почечной коликой и наблюдение за ним почти всегда позволяют выявить именно паралитический характер сопутствующей кишечной непроходимости (равномерное вздутие живота, прекращение перистальтики). Кроме того, боль и рвота возникают одновременно, тогда как при катастрофе в брюшной полости рвота обычно появляется спустя некоторое время после появления болей.

После окончания почечной колики обычно выделяется значительный объем мочи, в которой обнаруживается микро- или макрогематурия.

При бимануальной пальпации выявляется резкая болезненность в области почки, резистентность мышц на стороне заболевания. Иногда удается прощупать увеличенную и болезненную почку. В ряде случаев при почечной колике наблюдаются повышение температуры, озноб, лейкоцитоз при отсутствии других признаков мочевой инфекции и острого пиелонефрита.

Исследование мочи после стихания болевого приступа позволяет обнаружить свежие эритроциты или сгустки крови, белок, соли, лейкоциты, эпителий.

Обзорная рентгенография брюшной полости дает возможность исключить острую абдоминальную патологию. Кроме того, на рентгенограммах и урограммах могут выявляться пневматоз кишечника, более плотная тень пораженной почки и «ореол разрежения» в области околопочечных тканей при их отеке.
Внутривенная урография по изменению контуров чашечек и лоханки, смещаемости почки, характеру изгиба мочеточника и другим признакам позволяет выявить причину почечной колики (нефролитиаз, камень мочеточника, гидронефроз, нефроптоз и др.).

Значительную помощь в диагностике оказывает хромоцистоскопия. Отсутствие выделения из устья мочеточника на стороне болей метиленового синего, введенного в вену, или резкое его замедление (в норме появляется из устья мочеточника через 4 мин после введения в вену) всегда является неопровержимым доказательством блокады почки.

Когда диагноз почечной колики не вызывает сомнения, проводят сначала экстренные лечебные мероприятия, а затем срочно госпитализируют больного.

Необходимо уложить больного в постель, провести успокаивающую беседу. Для купирования болевого синдрома используют ненаркотические анальгетики в комбинации со спазмолитиком:

- например, ревалгин (метамизол натрия + питофенон + фенпивериния бромид); взрослым и подросткам старше 15 лет вводят внутривенно медленно 2 мл со скоростью 1 мл в течение 1 мин (при внутримышечном введении анальгетический эффект развивается через 16 мин); перед введением инъекционного раствора его следует согреть в руке, в период лечения препаратом не рекомендуется принимать этанол;

- кеторолак (кеторол) внутривенно 30 мг (1 мл); дозу необходимо вводить не менее чем за 15 с (при внутримышечном введении анальгетический эффект развивается через 30 мин);

- или спазмолитики; дротаверин вводят внутривенно медленно, 40-80 мг (2-4 мл 2\% раствора); допустимо в качестве спазмолитика использовать нитроглицерин под язык в таблетках (0,25 мг или 1/2 таблетки; 400 мкг или 1 доза спрея).

Среди спазмолитических препаратов важное место занимает гиосцина бутилбромид - антихолинергическое средство, блокирующее действие ацетилхолина, является агонистом эндогенных мускариновых рецепторов.

Гиосцина бутилбромид из всех селективных спазмолитических препаратов дольше всего применяется в Европе. Впервые препарат был зарегистрирован в Германии в 1951 г. В настоящее время он относится к одним из наиболее изученных в эксперименте и клинике из селективных в отношении желудочно-кишечного тракта (ЖКТ) спазмолитических препаратов. Препарат обладает высокой спазмолитической активностью - он в 44 
раза активнее дротаверина в подавлении сокращений, вызванных ацетилхолином; выпускается в форме ректальных свечей (суппозиториев) и таблеток. Активным веществом этого медикаментозного средства является гиосцина бутилбромид (10 мг в 1 таблетке или свече).

Таблетки белого цвета, двояковыпуклые, продолговатые и круглые, покрыты сахарной оболочкой. Выпускаются по 20 штук в блистерах. В картонной коробке - 1 блистер. Суппозитории для ректального введения - белого цвета или цвета слоновой кости, продолговатые, с гладкой поверхностью. Выпускаются по 5 штук в стрипах из алюминиевой фольги. В картонной пачке - 2 стрипа.

Кроме активного вещества, 1 таблетка гиосцина бутилбромида содержит еще и вспомогательные компоненты (винная кислота, стеариновая кислота, двуокись кремния коллоидная, крахмал растворимый, крахмал кукурузный и фосфат кальция двухосновный). Что касается свечей, то в 1 свече содержится 10 мг гиосцина бутилбромида, жир W45 твердый и вода.

Ректальные свечи взрослым и детям старше 6 лет назначают по 1-2 в прямую кишку 3 раза в день. По инструкции в таблетированной форме взрослым и детям старше 6 лет препарат желательно принимать по 1-2 таблетке 3 раза в сутки. Таблетки необходимо запивать водой.

Гиосцина бутилбромид воздействует преимущественно на М3-подтипы холинорецепторов, располагающихся в гладкомышечных клетках органов ЖКТ, пищеварительных желез и мочеполовой системы

Местное спазмолитическое действие объясняется ганглиоблокирующей и антимускариновой активностью препарата

Будучи четвертичным аммониевым производным, гиосцина бутилбромид не проникает через гематоэнцефалический барьер, поэтому его антихолинергическое влияние на центральную нервную систему отсутствует. Препарат обладает также низкой системной биодоступностью (<1\%), поэтому риск возникновения системных антихолинергических побочных эффектов ограничен.

Терминальный Т1/2 препарата после однократного применения внутрь в дозах 100-400 мг колебался от 6,2 до 10,6 ч. После применения препарата внутрь почечная элиминация составляет от 2 до 5\%, элиминация через кишечник 90\%. Необходим контроль частоты сердечных сокращений, АД, диуреза.

Экстренной госпитализации в урологическое отделение подлежат больные в случае:

- некупирующейся почечной колики;
- наличия клинических признаков осложнений;

- двусторонней почечной колики или при единственной почке.

Транспортировка больного осуществляется на носилках в положении лежа.

Если диагноз почечной колики вызывает сомнение, больных следует госпитализировать в приемное отделение многопрофильного стационара.

Допустимо амбулаторное лечение больных молодого и среднего возраста при их отказе от госпитализации в случаях:

- удовлетворительного стабильного состояния;

- отсутствия признаков осложнений;

- умеренного болевого синдрома;

- хорошего эффекта от введения анальгетиков;

- возможности амбулаторного обследования, контроля и лечения.

\section{Рекомендуемая литература}

Мазо Е.Б., Верткин А.Л. Почечная колика. Лечащий врач. 2008; 1.

Верткин А.Л., Мазо Е.Б., Дадыкина А.В., Лукашов М.И. Почечная колика. Лечащий врач. 2006; 7.

Косарев В., Бабанов С., Будаш Д. Профессиональные поражения почек и мочевыводящих путей. Врач. 2016; 5:4-10.

ПушкарьД.Ю., ЗайцевА.В., АлексанянЛ.А., Тополянский А.В. Неотложные мероприятия в некоторых экстренных случаях в урологии на догоспитальном этапе. Лечащий врач. 2002; 11.

Авдошин В.П., Андрюхин М.И., Ольшанская Е.В. Мочекаменная болезнь. Лечащий врач. 2008; 1.

Осипенко М.Ф. Абдоминальная колика: вопросы диагностики и подходы к лечению. РМЖ. 2013; 13.

Lacy B.E. on behalf of the study group. Fei Wang, Sujata Bhowal, Eckhard Schaefer. 2012, US Pilot Manuscript.

Maitai C.K., Njoroge D.K. A comparative study of two antispasmodic products: Buscopan and No-spa. East Afr Med J. 1985; 62: 480-5.

Скворцов В.В., Тумаренко А.В. Первая врачебная помощь при почечной колике. Справочник врача общей практики. 2010; 9: 32-6.

\section{RENAL COLIC}

V.V. Skvortsov, MD; A.V. Tumarenko; E.I. Kalinchenko, Cand. Med. Sci.; T.E. Saltovskaya; A.A. Chernyshova; M.A. Lukina

Volgograd State Medical University,

1, Pavshikh Bortsov Square, Volgograd, 400066, Russia

The paper presents the issues of etiology, pathogenesis, clinical symptoms, and approaches to the diagnosis and therapy of renal colic and urolithiasis.

Key words: urolithiasis, renal colic, diagnosis, emergency care, spasmolytics, cholinolytics, narcotic analgesics, novocaine blockades, thermal procedures, infusion therapy.

For reference: Skvortsov V.V., Tumarenko A.V., Kalinchenko E.I., Saltovskaya T.E., Chernyshova A.A., Lukina M.A. Renal colic. Meditsinskaya Sestra. 2018; 20 (6): 3-5. https://doi.org/10.29296/25879979-2018-06-01 